\title{
Treatment of accidental hypothermia: a prospective clinical study
}

\author{
I MCA LEDINGHAM, J G MONE
}

\section{Summary and conclusions}

A 15-year prospective study was carried out of 44 patients with accidental hypothermia (mean age 60 years) admitted to an intensive therapy unit. The lowest core temperature recorded in each patient ranged from 20.0 to $34 \cdot 3^{\circ} \mathrm{C}$. The precipitating factors were poisoning (by drugs, alcohol, or coal gas) in 25 cases and various illnesses in 19. Rewarming was achieved in 42 patients by applying a radiant heat cradle over the torso, and in two patients by mediastinal irrigation with warmed fluids. Twelve patients died, but only two during the period of rewarming.

Thus rewarming may be consistently and safely achieved irrespective of the cause of hypothermia, and normal body temperature may be regained as rapidly as is compatible with adequate tissue perfusion and oxygenation. Surface rewarming of the torso is perhaps the simplest technique available, but internal rewarming procedures may be desirable or essential in the presence of, for example, profound hypothermia, severe hypotension, or ventricular fibrillation. Mortality was attributable to underlying factors or disease and not to hypothermia.

\section{Introduction}

Accidental hypothermia is traditionally the pathophysiological state in which central temperature has been reduced unintentionally to below $35^{\circ} \mathrm{C}$. Two main subdivisions are recognised: (1) hypothermia due to exposure of otherwise healthy individuals to cold, wet, or windy conditions; and (2) hypothermia occurring in the very young or the elderly (often secondary to some underlying illness) and in the general population (secondary to drugs and alcohol). Patients in the second category are surprisingly common in urban populations, and mortality is high: the reported figures vary from $40 \%$ to over $80 \%{ }^{1}$ Some advances in treatment have been made within the past decade, but there is still no universally agreed policy. ${ }^{2}$ Several key issues remain unresolved including the optimum rate of rewarming, the need for intravenous fluids, the role of oxygen administration and positive-pressure ventilation, and the indications for drugs.

We have carried out a 15 -year prospective study of patients presenting with accidental hypothermia in an urban environment. During the course of the study we have made brief statements on treatment ${ }^{3}{ }^{4}$ but have not presented detailed results.

\section{Patients and methods}

From 1963 to 1978,44 patients suffering from accidental hypothermia were referred from the medical units and the accident and emergency department at this hospital. From 1968 treatment was carried out in the intensive therapy unit.

Intensive Therapy Unit, Western Infirmary, Glasgow G11 6NT I MCA LEDINGHAM, MD, FRCS(ED), reader in surgery J G MONE, MB, FFARCS, consultant anaesthetist

\section{MONITORING}

On admission the patient's general condition was preliminarily assessed and arterial blood samples withdrawn for detailed biochemical and haematological analyses. A chest radiograph and full-lead electrocardiogram were obtained. Radial artery and central venous catheters were inserted for measurement of heart rate, and systemic arterial and central venous blood pressure; thermocouples were placed in the rectum and on the great toe for measurement of central and peripheral temperatures. Heart rate, arterial pressure, temperatures, and the tracing from lead II of the electrocardiogram were continuously displayed on a bedside monitor. Respiratory rate and inspired oxygen concentration were recorded in patients breathing spontaneously, and more detailed information in those being ventilated. Bladder catheterisation permitted accurate measurement of urine output. No exhaustive investigation was carried out at this stage to elicit the cause of hypothermia.

\section{TREATMENT}

Rewarming was achieved in 42 of the patients by applying a radiant heat cradle over the torso, the skin being protected by a thin sheet. Active rewarming was discontinued at about $35^{\circ} \mathrm{C}$ to allow for the usual spontaneous further rise in temperature of $2-3^{\circ} \mathrm{C}$. The two patients not rewarmed by this method underwent thoracotomy and mediastinal irrigation with warmed fluids. Intravenous fluids, which were warmed before infusion, were administered to reduce haemoconcentration; restore circulating blood volume; and maintain arterial pressure, central venous pressure, and urine output at satisfactory levels.

Oxygen was administered to maintain the arterial pressure of oxygen $\left(\mathrm{PO}_{2}\right)$ (corrected for temperature) within the normal range; indications for intermittent positive-pressure ventilation included (1) a combination of hypoxaemia and arterial pressure of $\mathrm{CO}_{2}$ $\left(\mathrm{PCO}_{2}\right)$ over about $4.7 \mathrm{kPa}(35 \mathrm{~mm} \mathrm{Hg})$ (corrected for temperature); (2) evidence of deteriorating pulmonary gas exchange; (3) coma; and (4) cardiovascular instability. Throughout rewarming the cardiovascular and respiratory indices outlined above were observed carefully and appropriate action begun when required; biochemical and haematological disturbances were likewise detected early and remedied. No special consideration was given to the fact that the patients were hypothermic, although hypotension was more often tolerated without recourse to pharmacological agents, and arterial $\mathrm{PCO}_{2}$ was maintained at values below the normal range in patients receiving ventilation.

The patients were followed up for one month after the episode of hypothermia. Postmortem examination was performed in 10 of the 12 patients who died.

\section{RETROSPECTIVE STUDY}

During the period of the prospective study an additional 89 hypothermic patients were treated by other doctors at this hospital along conventional-that is, less aggressive-lines. These patients did not constitute a properly planned control group, but we nevertheless determined their fate retrospectively. We recovered 77 adequate case records, from which we made a preliminary analysis.

\section{Results}

The mean age of the 44 patients in the prospective study was 60 years, most being aged $40-70$ years. The lowest core temperature recorded in each patient ranged from 20.0 to $34.3^{\circ} \mathrm{C}$ (table I), and in 37 cases $(84 \%)$ was below $32.3^{\circ} \mathrm{C}$, the temperature indicating medically important primary hypothermia. ${ }^{5}$

Poisoning was the precipitating factor in 25 cases. Drugs were the 
TABLE I-Lowest recorded core temperatures in all 44 patients with accidental hypothermia 1963-78

$\begin{array}{lccccccccccccccc}{ }^{\circ} \mathrm{C} & 20 & 21 & 22 & 23 & 24 & 25 & 26 & 27 & 28 & 29 & 30 & 31 & 32 & 33 & 34 \\ \text { No of patients } & 1 & & & 3 & 2 & & 2 & 3 & 5 & 5 & 5 & 4 & 9 & 3 & 2\end{array}$

precipitating factor in 18: longer-acting barbiturates in two (plus nitrazepam (one case) and phenothiazine (one)); other barbiturates in eight (plus alcohol (one case) and trichloral (one)); and other drugs in eight (namely, tryptazole and alcohol, phenothiazine, meprobamate (two cases), fluphenazine, tryptophan, diazepam, and tryptazole). Alcohol was the precipitating factor in four patients (two of whom were taking pentobarbitone), and coal-gas poisoning in three. In the 19 remaining patients various illnesses were found: cardiovascular accident (four), endocrine disease (four), malnutrition and dehydration (three, in two of whom alcohol was also a precipitating factor), malignancy (two), myocardial infarction (one), pneumonia (one), old age (one), injury (one), skin disease (one), and mental disability (one).

\section{CLINICAL AND LABORATORY DATA}

Heart rates tended to be slower at lower temperatures, but the relation was not as striking as might have been expected. There was no consistent relation between arterial blood pressure and temperature, although in 10 of the earlier patients initial blood pressure on admission was unrecordable. (This occurred before measurement of intra-arterial blood pressure became routine.) Of the 34 patients whose admission electrocardiogram had been retained, over half had arrhythmias, including seven patients with atrial fibrillation and three with ventricular fibrillation (of whom two survived).

Seventeen patients $(39 \%)$ had obvious respiratory inadequacy on clinical examination: nine were apnoeic and eight nearly so. Initial chest $x$-ray films showed patchy opacification in 12 out of 30 patients $(40 \%)$, and five more patients subsequently developed radiological changes. Blood-gas analysis confirmed the high incidence and severity of disturbances of pulmonary gas exchange. In most of the patients in whom analysis was performed during spontaneous air breathing arterial $\mathrm{Po}_{2}$ was less than $7 \cdot 3 \mathrm{kPa}$ ( $55 \mathrm{~mm} \mathrm{Hg}$; fig 1); and in those breathing oxygen either spontaneously or via a ventilator the mean alveolar-arterial differences in $\mathrm{Po}_{2}$ were 33 and $47 \mathrm{kPa}$ (248 and 353 $\mathrm{mm} \mathrm{Hg}$ ) respectively. Mean arterial $\mathrm{PCO}_{2}$ in the whole group was 4.3 $\mathrm{kPa}$ (32 $\mathrm{mm} \mathrm{Hg}$; fig 2), which accounted for a normal mean arterial $\mathrm{pH}$ of 7.38 units in the presence of a mean base deficit of $9 \mathrm{mmol}(\mathrm{mEq}) / \mathrm{l}$.

The biochemical findings were similar to those previously reported in patients with accidental hypothermia. ${ }^{6}$ Haemoconcentration was common, as were thrombocytopenia and leucocytosis as shown by

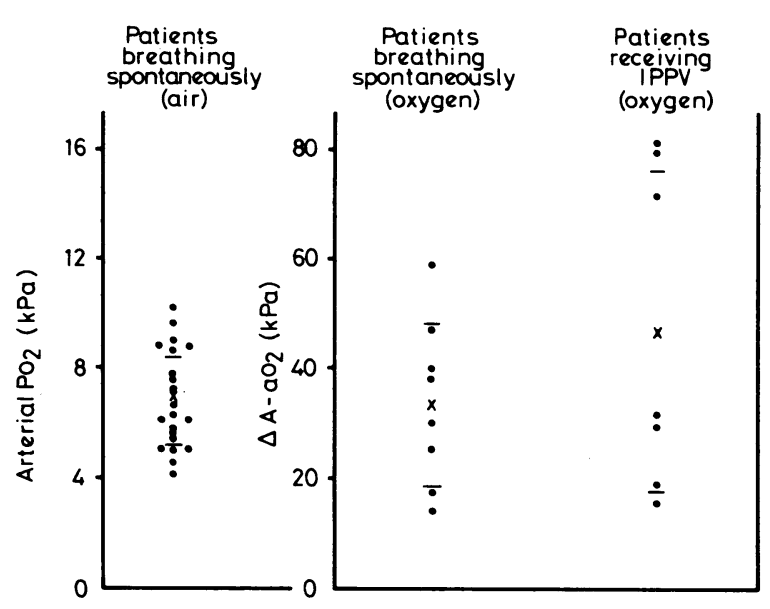

FIG 1-Arterial $\mathrm{Po}_{2}$ in patients breathing (air) spontaneously, and alveolar-arterial $\mathrm{PO}_{2}$ difference $\left(\triangle \mathrm{A}-\mathrm{aO}_{2}\right)$ in patients breathing (oxygen) spontaneously and receiving ventilation (IPPV) at lowest temperature; crosses indicate means, and bars standard deviations.

Conversion: SI to traditional units-Respiratory indices: $1 \mathrm{kPa} \approx 7.5 \mathrm{~mm} \mathrm{Hg}$. haematological analysis, although the leucocytosis generally became less pronounced once the volume of circulating fluid had been restored.

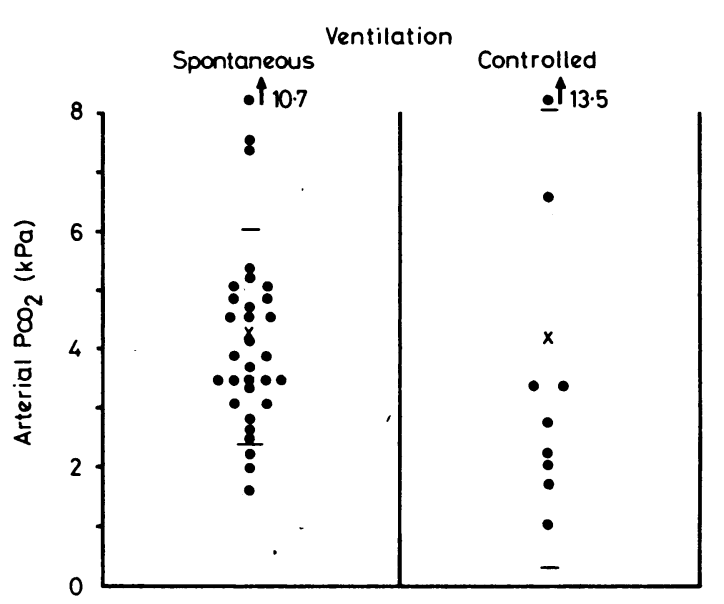

FIG 2-Arterial $\mathrm{PCO}_{2}$ in patients breathing spontaneously and receiving ventilation; crosses indicate means, and bars standard deviations.

Conversion: SI to traditional units-Respiratory indices:

$1 \mathrm{kPa} \approx 7.5 \mathrm{~mm} \mathrm{Hg}$.

\section{TREATMENT}

No patient was adversely affected by any of the manoeuvres used for monitoring purposes or treatment. Reflex cardiac slowing and induced arrhythmias were not seen.

Rewarming was achieved at a mean rate $\left( \pm \mathrm{SEM}\right.$ ) of $1.13 \pm 0.09^{\circ} \mathrm{C}$ hour. The mean duration of rewarming was $8.03 \pm 0.85$ hours. Figure 3 shows the course of uneventful active rewarming; the patient breathed spontaneously throughout. Most patients (41) received some intravenous fluids during this period, the mean volume infused being $2 \cdot 1 \pm 0 \cdot 21$. Dextrose $(5 \%)$ and saline were the fluids most frequently infused, but plasma and blood were given occasionally; potassium was administered as indicated by sequential biochemical analyses; calcium was not normally given. Oxygen (mean maximum concentra-

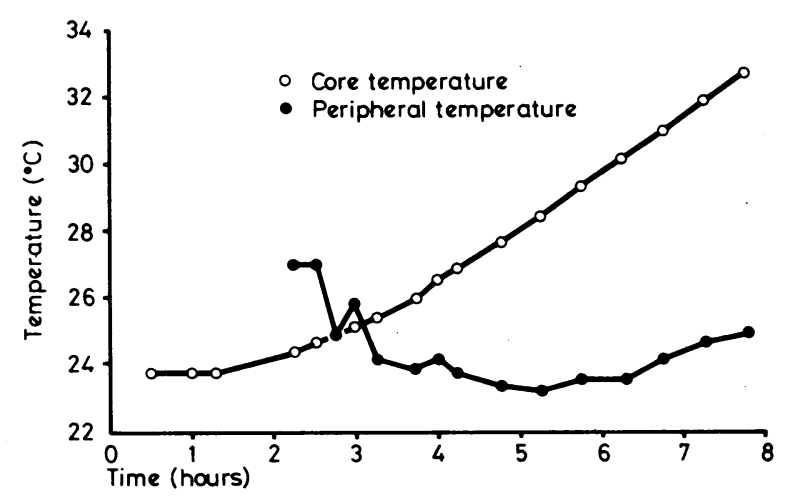

FIG 3-Uneventful rewarming from $23.6^{\circ} \mathrm{C}$ in a 48 -year-old man who had taken butobarbitone and alcohol before prolonged exposure to cold.

tion $65 \%$ ) was administered to 40 patients, and intermittent positivepressure ventilation with warmed humidified gas to $21(48 \%)$. At the end of rewarming the standard criteria for weaning from the ventilator were observed, and adequate spontaneous ventilation was usually achieved without difficulty.

The most troublesome problem during rewarming was hypotension, which was regarded as more severe than usual (systolic blood pressure less than about $70 \mathrm{~mm} \mathrm{Hg}$ ) in 14 of the 44 patients $(32 \%)$. Seven of these patients received drugs aimed at increasing blood pressure and thereby improving perfusion to vital organs. Four were given the vasoconstrictor metaraminol: one responded well, a second had a variable response, and two showed no response; while three received 
drugs with a major inotropic action on the heart (dopamine and isoprenaline); all responded well, and urine output improved appreciably in the two given dopamine. One patient was given the alphaadrenotropic blocking agent thymoxamine because of persistent vasoconstriction towards the end of rewarming; a moderate response occurred.

Steroids had been administered to seven patients before referral; only small doses had been given and the effect was impossible to judge. Antibiotics were not administered prophylactically, but 24 patients $(55 \%)$ received various antibiotics when bacteriological examination confirmed clinically important infection (usually of respiratory origin).

\section{MORTALITY}

The overall mortality in the prospective study was $27 \%$ (12 patients) Only two patients $(5 \%)$ died during rewarming; both deaths occurred in the early years of the study (1965 and 1968), one because mechanical ventilation was stopped prematurely and the other from inadequate fluid repletion. The remaining 10 patients all died after regaining normal body temperature (table II).

TABLE II-Details of patients who died

\begin{tabular}{|c|c|c|c|c|c|}
\hline $\begin{array}{l}\text { Case } \\
\text { No }\end{array}$ & $\underset{\text { treated }}{\text { Year }}$ & $\begin{array}{l}\text { Age } \\
\text { (years) } \\
\text { and } \\
\text { sex }\end{array}$ & $\begin{array}{l}\text { Precipitating and } \\
\text { associated factors }\end{array}$ & $\begin{array}{l}\text { Day } \\
\text { of } \\
\text { death }\end{array}$ & Cause of death \\
\hline 1 & 1965 & $77 \mathrm{M}$ & Coal-gas poisoning & $1^{*}$ & Respiratory failure during \\
\hline 2 & 1968 & $65 M$ & Alcoholism; anaemia & $1^{*}$ & Cardiac failure during \\
\hline 3 & 1970 & $80 M$ & $\begin{array}{l}\text { Coal-gas poisoning; } \\
\text { cerebrovascular accident }\end{array}$ & 2 & $\begin{array}{l}\text { rewarming } \\
\text { Cerebrovascular accident } \dagger\end{array}$ \\
\hline $\begin{array}{l}4 \\
5\end{array}$ & $\begin{array}{l}1967 \\
1970\end{array}$ & $\begin{array}{l}84 \mathrm{~F} \\
69 \mathrm{~F}\end{array}$ & $\begin{array}{l}\text { Cerebrovascular accident } \\
\text { Myocardial infarction }\end{array}$ & $\begin{array}{l}3 \\
4\end{array}$ & $\begin{array}{l}\text { Cerebrovascular accident } \dagger \\
\text { Further myocardial } \\
\text { infarction }\end{array}$ \\
\hline 6 & 1974 & $66 \mathrm{M}$ & Hypertension & 4 & Subarachnoid haemorrhage \\
\hline 7 & 1974 & $56 \mathrm{M}$ & $\begin{array}{l}\text { Chronic respiratory } \\
\text { disease; diarrhoea and } \\
\text { vomiting; dehydration }\end{array}$ & 4 & $\begin{array}{l}\text { Cardiac arrest (serum } \\
\text { calcium } 1.2 \mathrm{mmol} / 1 \\
4.8 \mathrm{mg} / 100 \mathrm{ml})\end{array}$ \\
\hline $\begin{array}{l}8 \\
9\end{array}$ & $\begin{array}{l}1969 \\
1978\end{array}$ & $\begin{array}{l}59 M \\
78 M\end{array}$ & $\begin{array}{l}\text { Pituitary tumour } \\
\text { Tuberculous } \\
\text { bronchopneumonia; } \\
\text { cerebrovascular accident }\end{array}$ & $\begin{array}{r}4 \\
10\end{array}$ & $\begin{array}{l}\text { Meningitis } \\
\text { Acute renal failure; } \\
\text { cerebral softening }\end{array}$ \\
\hline 10 & 1969 & $60 M$ & Reticulosis; anaemia & 11 & $\begin{array}{l}\text { Reticulosis; } \\
\text { bronchopneumonia }\end{array}$ \\
\hline 11 & 1964 & $69 \mathrm{~F}$ & $\begin{array}{l}\text { Myxoedema; rheumatoid } \\
\text { arthritis; anaemia; } \\
\text { myocardial infarction }\end{array}$ & 12 & $\begin{array}{l}\text { Septic shock; perforated } \\
\text { stercoral ulcer }\end{array}$ \\
\hline 12 & 1974 & $80 \mathrm{~F}$ & $\begin{array}{l}\text { Melaena; dehydration; } \\
\text { inanition }\end{array}$ & 19 & Myocardial infarction \\
\hline
\end{tabular}

* Patient died during rewarming.

† Postmortem examination was not carried out.

We considered in greater detail three of the several factors that might have been expected to affect the ultimate outcome in patients suffering from hypothermia-namely, age, temperature on admission, and nature of the principal precipitating condition. The mean age of non-survivors $(71 \pm 9$ years) was significantly greater $(p<0.001)$ than that of survivors ( $50 \pm 17$ years), but there was no significant difference in temperature between the two groups. The patients in whom poisoning was the principal precipitating factor appeared to have a considerably better prognosis (two out of 25 died) than the others (10 out of 19 died; $\left.\chi^{2}=8.7, p<0.005\right)$. The temperature on admission in the two groups did not differ $\left(28 \cdot 8 \pm 0 \cdot 78^{\circ} \mathrm{C}\right.$ in the poisoned patients and $29.6+0.55^{\circ} \mathrm{C}$ in the others), but the mean age of the two groups was significantly different $(\mathbf{4 4} \pm 15$ years in the poisoned patients who survived and $64 \pm 10$ years in the non-poisoned patients who survived; p $<0.001$ ); there was no significant difference in mean age between the two groups of patients who died. Age did not significantly differentiate survivors and non-survivors in the group of non-poisoned patients.

Analysis of the data from the retrospective group of 77 patients showed that most were aged 60-90 years and the lowest individual recorded temperatures ranged from 20.0 to $34.7{ }^{\circ} \mathrm{C} ; 54(70 \%)$ were below $32 \cdot 2^{\prime} \mathrm{C}$. The overall mortality was $60 \%$ (46 patients), 36 of these patients $(78 \%)$ dying during rewarming in the first three days after admission. The mean age of the non-survivors was $73 \pm 2$ years and of the survivors $67+3$ years; the mean central temperature of the nonsurvivors was $29.6 \pm 0.5^{\prime \prime} \mathrm{C}$ and of the survivors $31.7 \pm 0.4^{\circ} \mathrm{C}$ $(p<0.005)$. Nineteen of the 77 patients were hypothermic as a result of drug or alcohol abuse, alcohol abuse being more common; six of these patients died ( $32 \%$ ). Most of the patients (58) had either some serious underlying illness or no obvious cause for hypothermia; 40 of these patients died $(69 \%)$. The difference in mortality between the patients who had abused drugs or alcohol and the others was significant $\left(\chi^{2}=6.8 ; p<0.01\right)$.

\section{Discussion}

\section{TREATMENT}

One of the more controversial aspects of treatment concerns the rate and technique of rewarming. Rapid external rewarming has been used largely, though by no means exclusively, for younger patients suffering from hypothermia of fairly brief duration, ${ }^{7-9}$ while rapid internal rewarming has usually been reserved for patients with profound hypothermia whose resuscitation by simpler methods proved to be difficult or impossible. ${ }^{10-12}$

In the elderly rapid external rewarming fell into disrepute after the reports of Rees ${ }^{13}$ and Duguid et al ${ }^{14}$ : the latter attempted active rewarming in six patients, all of whom died. Since then most doctors concerned with managing urban patients with hypothermia have opted for passive external rewarming. $\mathrm{Re}-$ storation of normal body temperature by using this technique may take 24 hours, or longer if there are cardiorespiratory complications, with the result that many patients die while still hypothermic (41 out of 100 consecutive patients in one series $\left.^{15}\right)$.

Only two patients in the present series died during the rewarming period-and none in the past decade. Thus active rewarming is safe even in the elderly hypothermic patient, and previously reported problems associated with active rewarming of these patients probably had other explanations-for example, hypoperfusion and hypoxia. The importance of fluid repletion and correcting hypoxaemia, including using mechanical ventilation if indicated, is now clear. ${ }^{16}$ Cardiorespiratory collapse during rewarming may be avoided, and the incidence of longerterm pulmonary complications appears to be reduced.

This study has also shown that invasive monitoring and treatment manoeuvres are not in themselves harmful. If ventricular fibrillation was precipitated by these manoeuvres ${ }^{517}$ factors other than hypothermia per se were apparently responsible-for example, hypoxia, ${ }^{18}$ hypotension or acidosis, ${ }^{19}$ or awkward movement. ${ }^{20}$

The complex interaction between drugs and hypothermia suggests that the use of all drugs should be restricted during rewarming. In the present study vasoactive agents were occasionally used for persistent hypotension. Two points may be noted: the hypotension of hypothermia may be more apparent than real (because of diminished pulse pressure), and it usually responds to fluid infusion alone. Vasoconstrictors have proved disappointing, but selective use of inotropic agents may be rewarding. ${ }^{21} 22$

\section{MORTALITY}

Comparing mortality between groups of patients is complicated by the variability of such factors as age, severity and duration of hypothermia, and nature of precipitating condition. Thus although the overall mortality of $27 \%$ in the prospective study is the lowest recorded, it was favourably influenced by the proportion of patients admitted with hypothermia induced by poisoning. More important, we believe, is the elimination of deaths during the rewarming phase, irrespective of the factor(s) precipitating the hypothermia.

A more aggressive approach to treatment (including rewarming) has the advantages that the period of close monitoring may be reduced and the underlying condition more rapidly diagnosed. Whether many lives are saved remains to be ascertained by controlled study, but the evidence suggests that few of the patients in the prospective study died of factors attributable to hypothermia (particularly respiratory complications). This 
could not be stated with any conviction for the patients in the retrospective study, many of whom died while still hypothermic and before a definite diagnosis was made.

\section{Refcrences}

${ }^{1}$ Mills GL. Accidental hypothermia in the elderly. Br $\mathcal{F}$ Hosp Med 1973; 10:691-9.

2 Gregory RT, Doolittle WH. Accidental hypothermia. Part II: Clinical implications of experimental studies. Alaska Med 1973;15:48-52.

${ }^{3}$ Ledingham IMcA, Mone JG. Treatment after exposure to cold. Lancet $1972 ; \mathrm{i}: 534-5$.

- Ledingham IMcA, Mone JG. Accidental hypothermia. Lancet 1978;i:391.

5 Hockaday TDR, Fell RH. Accidental hypothermia (Hockaday) with an appendix on blood gas and acid-base measurements (Fell). $\mathrm{Br} \mathcal{f} \mathrm{Hosp}$ Med 1969;2:1083-93.

- MacLean D, Emslie-Smith D. In: Accidental hypothermia. Oxford: Blackwell, 1977:340.

7 Pugh LGCE. Accidental hypothermia in walkers, climbers, and campers: report to the Medical Commission on Accident Prevention. $\mathrm{Br} \mathrm{Med} \mathrm{f}$ $1966 ; \mathrm{i}: 123-9$.

${ }^{8}$ Keatinge WR. Survival in cold water: the physiology and treatment of immersion hypothermia and of drowning. Oxford: Blackwell Scientific, 1969.

- Fernandez JP, O'Rourke RA, Ewy GA. Rapid active external rewarming in accidental hypothermia. $\mathcal{F} A M A 1970 ; 212: 153-6$.
${ }^{10}$ Linton AL, Ledingham IMcA. Severe hypothermia with barbiturate intoxication. Lancet $1966 ; \mathrm{i}: 24-6$.

11 Fell RH, Gunning AJ, Bardhan KD, Triger DR. Severe hypothermia as a result of barbiturate overdose complicated by cardiac arrest. Lancet $1968 ; \mathrm{i}: 392-4$

12 Soung LS, Swank L, Ing TS, et al. Treatment of accidental hypothermia with peritoneal dialysis. Can Med Assoc $\mathcal{F} 1977 ; 117: 1415-6$.

13 Rees JR. Accidental hypothermia. Lancet 1958;i:556-9.

14 Duguid H, Simpson RG, Stowers JM. Accidental hypothermia. Lancet 1961 ;ii :1213-9.

15 MacLean D, Emslie-Smith D. In: Accidental hypothermia. Oxford: Blackwell, 1977:392.

${ }^{16} \mathrm{McNicol} \mathrm{MW}$. Respiratory failure and acid-base status in hypothermia. Postgrad Med F 1967;43:674-6.

17 Cooper KE, Sellick BA. Physiological considerations. In : Cooper KE, Ross DN, eds. Hypothermia. London: Cassell, 1960:15.

18 Lloyd EL. Treatment after exposure to cold. Lancet 1972;i:491-2.

19 Jones RHT, Bourdillon RE, Finn R, Martindale K. Hypothermia associated with pneumonia and acidosis. Postgrad Med f 1966;42:273-5.

${ }^{20}$ Freeman J, Pugh LGCE. Hypothermia in mountain accidents. Int Anesthiol Clin 1969;7:997-1007.

${ }^{21}$ MacLean D, Murison J, Griffiths PD. Acute pancreatitis and diabetic ketoacidosis in accidental hypothermia and hypothermic myxoedema. Br Med F 1973;iv:757-61.

${ }^{22}$ Harari A, Regnier B, Rapin M, Lemaire F, LeGall JR. Perturbations hémodynamiques au cours des hypothermies accidentelles profondes et prolongées. Nouv Presse Med 1974;3:2184.

(Accepted 12 February 1980)

\title{
Paget's disease of bone: the Lancashire focus
}

\author{
D J P BARKER, A T CHAMBERLAIN，P B GUYER，M J GARDNER
}

\section{Summary and conclusions}

The radiological prevalence of Paget's disease of bone has been studied in 31 towns in Britain. A remarkably localised area of high prevalence has been shown in Lancashire. Although environmental influences seem dominant in the aetiology of the disease, no hypothesis about the environmental cause of the Lancashire focus can be advanced.

\section{Introduction}

In a recent survey of the radiological prevalence of Paget's disease of bone in 14 towns in England and Wales the highest prevalences recorded were in three towns in Lancashire. ${ }^{1}$ To investigate further this apparent focus of high prevalence in Lancashire, and to define its boundaries, we extended the survey to include an additional 17 towns.

\section{Methods}

The 17 towns were Aberdeen, Birkenhead, Blackpool, Burnley, Carlisle, Chester, Glasgow, Lancaster, Macclesfield, Middlesbrough, Newcastle upon Tyne, Oldham, Portsmouth, Rochdale, Warrington,

MRC Environmental Epidemiology Unit, South Block, General Hospital, Southampton SO9 $4 \mathrm{XY}$

D J P BARKER, PHD, FRCP, professor of clinical epidemiology

A T CHAMBERLAIN, BSC, research assistant

M J GARDNER, BSC, PHD, reader in medical statistics

Department of Radiology, General Hospital, Southampton SO9 4XY P B GUYER, DM, FRCR, consultant radiologist
Whitehaven, and Wigan. They were selected to include areas of Britain not studied in the initial survey, and to provide additional data on Lancashire and the towns bordering it. The survey method was identical with that used previously. ${ }^{1}$ In each town a sample of abdominal radiographs of people aged 55 and over was taken from the stored films within the radiological department of a general hospital. The selected films showed the entire pelvis and sacrum, the femoral heads, and all lumbar vertebrae-sites that are affected in $95 \%$ of patients with Paget's disease.

Wherever possible samples of about 1000 radiographs were drawn for each town, with similar numbers for men and women. In some towns the records systems were such that retrieval of radiographs, of the kind required and for patients of known age, was excessively time-consuming. In these circumstances smaller size samples were used. The films were initially classified by a trained observer (ATC) into three groups: positive (unequivocal signs of Paget's disease) doubtful, and negative. A second observer (PBG, a radiologist) then examined all the positive and doubtful films and a one-in-ten sample of the negative ones. Standardised criteria were used for the diagnosis of Paget's disease. In the previous survey the radiologist's observations were shown to have a high level of repeatability. After completion of the present survey a sample of 109 films from six towns was reexamined to determine whether this level of repeatability had been maintained.

\section{Results}

The table shows the prevalence of Paget's disease in the 17 towns, together with those in the 14 towns in the previous survey. The prevalence rates for each sex were directly standardised to allow comparisons corrected for the differing age distributions of the subjects in the various towns. The standardisation procedure used five-year age distributions from 55 to 90 and over. The combined population of the 14 towns was again used as the standard so that results of the two surveys are directly comparable. In the table the towns are listed in descending order of the overall age- and sexstandardised prevalences (final column), which varied from $8.3^{\circ} \%$ in 